\title{
Barriers to the Utilisation of Counselling Services by International Students
}

\author{
Alexa Kambouropoulos, ${ }^{1, *}$ \\ ${ }^{1}$ School of Psychology, Counselling and Psychotherapy, Cairnmillar Institute, Melbourne, Australia \\ *Correspondence: School of Psychology, Counselling and Psychotherapy, Cairnmillar Institute, Melbourne, \\ Australia. Tel: 61-3-9813-3400. E-mail: alexa.kambouropoulos@cairnmillar.edu.au \\ Received: April 7, $2015 \quad$ Accepted: June 12, $2015 \quad$ Online Published: August 26, 2015 \\ doi:10.5430/wje.v5n5p1 URL: http://dx.doi.org/10.5430/wje.v5n5p1
}

\begin{abstract}
International students are particularly affected by issues related to physical health, academic studies, and social and psychological matters. Despite sometimes-enormous emotional distress, there is evidence to suggest that these students are reticent to use counselling services to address these issues. The purpose of this study is to examine the rate of utilisation of counselling services by students at two Australian university campuses. Ninety participants completed a survey that examined their help-seeking behavior, the barriers that hindered them from seeking counselling, and how they eventually came to access the service. Follow-up interviews with a subset of these students $(n=21)$ were used to gain more detailed information about their use and experience of counselling services. Counsellors were also interviewed to obtain their perspective on these issues. It was found that several factors hindered students' use of counselling services and that an overwhelming majority seek help from their friends and other fellow international students rather than counselling services. However, some sought assistance unilaterally, or by referral from academic staff. It was concluded that international students were indeed reticent to attend counselling services, and there is a strong need for counselling services to be aware of cultural attitudes that act as a blockage to their utilisation.
\end{abstract}

Keywords: globalisation; international students; counselling; referral behavior

\section{Introduction}

The current climate of globalisation has brought with it a readiness amongst countries to exchange students. According to Australian Education International (AEI), the government body charged with monitoring the extent of international student traffic into Australia, international student data for 2009 shows there were 631,935 enrolments by full-fee paying international students in Australia on a student visa. This represents an increase of 16.8 percent on 2008 enrolments and compares with growth of 20.2 percent between 2007 and 2008. In 2009, year-to-date enrolments exceeded 600,000 for the first time.

Of international higher education enrolments in 2009, 72.4 percent came from Australia's top 10 markets, which include China, India, Republic of Korea, Thailand, Nepal, Vietnam, Malaysia, Indonesia, Brazil, and Saudi Arabia. China and India are the largest source of both enrolments and commencements, accounting for 18 percent and 25.4 percent growth, respectively, in 2008 (AEI, 2009). According to the AEI, education exports increased from $\$ 12.2$ billion in 2007 to $\$ 15.7$ billion in 2008, making education Australia's third largest export industry.

\section{Review of Literature}

Over the years, many studies have examined the type of problems international students experience while studying abroad. These concerns can be divided into several categories such as academic, social/psychological, and adjustment (Arthur, 2004; Bayley, Fearnside, Arnol, Misiano, \& Rottura, 2002; Hechanova-Alampay, Beehr, Christiansen, \& Horn, 2002; Poyrazli, Arbona, Bullington, \& Pisecco, 2001).

Another area that previous research has focused on is the utilisation of counselling services by international students. Mori (2002) identified several factors that inhibit utilisation of these. International students' unfamiliarity with the basic concepts of counselling seems to lead to their negative or inappropriate expectations of counselling. According to 
Mori, given that the majority of counsellors are from a Euro-American culture, international students may be suspicious of counsellors' motives for helping them. Mori also argued that the most important obstacle to international students' use of services is the shortage of culturally knowledgeable and sensitive counsellors.

Brinson and Kottler (1995), in their study, showed that some minority groups may consider the practice of counselling to be a form of "mind control" and that cultural difference in basic beliefs about mental health problems may be a hindrance to the use of counselling services. In some cases, students also feared that they will be sent home as failures because of the necessity for formal counselling (Boyer \& Sedbacek, 1989, cited in Mori, 2002). Uba's (1994) work on Asian Americans provides further explanations for the under-utilisation of mental health services, including cultural values and attitudes that inhibit self-referral and the stigma associated with mental health problems. Talking about personal problems is not seen as an appropriate way to deal with problems, especially among people of South East Asian culture, where feelings are considered as private matters. In Uba's (1994) study, client suspiciousness of non-Asian American counselors also constitutes a barrier to service utilization. Ignorance of available services, lack of financial resources on the part of the individual seeking counselling, geographic inaccessibility of services, and shortage of culturally sensitive personnel are other reasons why mental health services have not been sought (Uba, 1994).

In their study on the counselling expectations of 100 international students attending American universities, Bradley, Parr, Lan, Bingi, and Gould (1995) found that help-seeking behavior was a major contributor to students' under-utilisation of counselling services. Seeking help from friends is generally the first port of call, followed by seeking help from family members. It is likely that students will turn to professors and other academic staff before personnel directors, before counsellors. These findings are supported by Lin (1996) who contends that due to the stigma of mental health, many students from Asian countries do not seek professional psychological help unless they have exhausted their support system. Thus, they are likely to be in subjective crisis when they do eventually reach out to counsellors.

A study by Yi, Lin, and Kishimoto (2003) drew on data of self-identified international students who visited the counselling center between 1992 and 1998. Results found that more undergraduates (57.6\%) were more likely to be referred by faculty advisor or staff member than graduate students. In that study, 57.8 percent of students utilized the services for personal problems, 22 percent for academic issues, and 8.9 percent for career problems.

Kambouropoulos' (2008) study of 90 international students at two Australian universities found international students do not adequately utilise counselling services despite the extreme concerns they face in relation to academic, social, and emotional well-being.

Although a number of studies consistently show that under-utilisation is a critical issue with international students (Bradley et al., 1995; Mori, 2000; Nilsson, Berkel, \& Lucas, 2004; Uba, 1994; Yi et al., 2003), there is a paucity of research on the utilisation rate of counselling services by international students in Australia. Hence, to examine the extent of this problem, this study sought to understand students' help-seeking behavior and the path by which they eventually sought out counselling, as well as the barriers that hindered them from seeking this. In order to produce a more comprehensive view of this problem so that a more holistic approach to the utilisation of counselling services could be suggested, this study has compared the student-reported perspective with those reported by university counsellors having frequent contact with such students. Utilisation is defined as "help-seeking behavior in which the service of the mental health system is used" (Sue, Zane, \& Young, 1994).

\section{Methodology}

A questionnaire- and interview-based qualitative approach was used to examine the utilisation of counselling services by international students. Two large Victorian universities were selected for this study. Participants were recruited from the International Student Association at each campus after obtaining ethical consent from the Human Research Ethics Committee of each university. The data was collected from both undergraduates and postgraduates international students comprising of 52 males and 38 females from South East Asia (Malaysia, Singapore, and Indonesia), the Sub Continent (India), and Europe. For the purpose of this paper, the data of the two institutions is synthesised and discussed together.

\subsection{Questionnaire}

Prior to the preparation of the questionnaire, informal focus groups were convened wherein typical adjustment issues currently being experienced by international students, which prompted them to seek counselling, were identified. These then informed the final structure and content of the questionnaire used in the formal study. 
The questionnaire had two parts. The first section sought demographic data related to the student's course of study, education level attained, country of origin, gender, marital status, and duration of residency up to that point. The second section asked students to self-identify their help-seeking behavior (e.g., friends, family, Chaplin, counsellor, lecturer), the type of personal barriers that may hinder them from seeking counselling, and how they eventually came to access the service (e.g., referred or self-refereed).

\subsection{Follow-Up Personal Interviews}

Students completing the questionnaire were invited to attend personal interviews where the points identified in Section 2 could be further explored. Twenty-one students (16 females and 5 males) agreed to this. A semi-structured interview approach was adopted using a set of general questions based upon what the students had reported in the questionnaire. This allowed insights into their use of counselling services and provided greater certainty in identifying the student's primary motivation for accessing counselling. All the names of students (and counsellors) reported in this study are pseudonyms.

Twelve counsellors predominantly Anglo-Saxon from counselling services at the students' institutions, were interviewed to determine the rate of utilisation of counselling services by students and what they saw as the barriers for students in using such services. Counsellors who had available time as well as personal and professional interest in counselling across cultures participated in the study. The questions posed to counsellors at the interview were mailed to them in advance. Transcripts of the interviews were checked by the counsellors for accuracy.

\section{Analysis}

SPSS was used to analyze both the demographic data (Section 1), and student's rate of utilising counselling services (Section 2). The latter were summarised, tabulated, and compared. The interview transcripts of students and counsellors were read separately and in conjunction by the researcher to find patterns, themes, and insights. Merriam's (2002) comparative analysis methodology was adopted because of the qualitative nature of the study. This method argues that the systematic and constant making of comparisons is essential to conceptual development at all levels in the analysis of qualitative data.

\section{Results}

\subsection{Student Questionnaire}

Table 1 summarises the demographic data of the participants. Students from South East Asia comprised three-quarters of the cohort (75.6\%), followed by students from India (22.2), and Europe (2.2\%).

Table 1. Participant Characteristics

\begin{tabular}{llcc}
\hline & Characteristics & n & \% \\
\hline Sex & Female & 37 & 41.1 \\
Marital status & Male & 53 & 58.9 \\
& & & \\
& Unmarried & 80 & 88.9 \\
Country of origin & Married & 10 & 11.1 \\
& Sub-continent & 20 & 22.2 \\
& SE Asia & 68 & 75.6 \\
& Europe & 2 & 2.2 \\
Study level & Undergraduate & 63 & 70.0 \\
& Postgraduate & 27 & 30.0 \\
Faculties & Business/Economics & & 30.0 \\
& IT & 27 & 18.9 \\
& Engineering & 17 & 17.8 \\
& Medicine & 16 & 8.9 \\
& Science & 8 & 8.9 \\
& Law/Arts & 8 & 8.9 \\
& Education & 8 & 6.6 \\
\hline
\end{tabular}


More than two thirds $(70 \%)$ of the sample were undergraduates, the mean age of the students was 23.9 years old, and the number of male participants exceeded the females ( $\mathrm{n}=53$ and 38 respectively). Thirty percent of students were studying in the Faculty of Business and Economics, followed by Information Technology (18.9\%), and Engineering $(17.8 \%)$, while the others were in Medicine, Science, Education, and Law/Arts. An overwhelming majority of students were unmarried (88.9\%).

\subsection{Help-seeking Behaviour}

The rate of utilisation of counselling services by students (by gender) is summarised in Table 2. The results indicate that just under half of the students $(45.5 \%)$ did not use counselling despite the need for this service, while a third of students drew on services for help. A quarter of international students did not require any assistance.

Table 2. Utilization of Counseling Services of International Students by Gender $(\mathrm{n}=90)$

\begin{tabular}{llllll}
\hline & $\begin{array}{c}\text { Did not use } \\
\text { counseling }\end{array}$ & Used counseling & $\begin{array}{c}\text { Never } \\
\text { required }\end{array}$ & Did not respond & Total \\
\hline Male & 25 & 18 & 9 & 1 & 53 \\
Female & 16 & 15 & 6 & 0 & 37 \\
Total & $41(45.5 \%)$ & $33(36.7 \%)$ & $15(16.7 \%)$ & $1(1.1 \%)$ & $90(100 \%)$ \\
\hline
\end{tabular}

Results in Table 3 demonstrate that many students used a combination of help-seeking behaviours when encountering challenging problems. While the majority of students sought help from their "friends," over half of them approached students from "their own country" and less than half sought support from "other international" students on campus. Less than one of quarter of students stated that they would seek assistance from a "counsellor."

Table 3. International Students' Help-Seeking Behavior

\begin{tabular}{lc}
\hline & $\mathbf{\%}$ \\
\hline Friends & $86.7 \%$ \\
Students from own country & $45.6 \%$ \\
Other international students & $40 \%$ \\
Counselor & $22.2 \%$ \\
\hline
\end{tabular}

Of the 21 students who participated in the follow-up interviews, an overwhelming majority reported that they would approach their "friends" and "students from their own country" for help. One-third (7) indicated that they would use a "counsellor" and 11 stated they would use the "international student advisor."

According to students, their reason for seeking help from friends is largely that it was the most "natural" and "acceptable" thing for them to do. In this instance, students felt at ease and comfortable with someone with whom they had an existing relationship. For example:

Back in our country we talk and share problems by talking to friends, it's not the same as talking to counsellors. We share strategies as to how to cope with problems. (So Sang)

Friends are people whom I interact mostly with, I am most open to them and they know more about me as a person from Bangladesh cultural context. So, in this case I do not have to explain to them who I am. That helps because they know how I feel about a problem, they know how to give advice or a solution. I feel more comfortable with them. (Rohan)

Please note that in this, and subsequent quotations, no effort has been made to correct the English expression.

\subsection{Barriers to Counselling}

The students identified personal barriers to counselling; these are summarised in Table 4. The results demonstrate that over one third of students found "confidentiality issues" to be a personal barrier while one third found "invasion of privacy" and "fear of the unknown." Less than one quarter of the students found "cultural difference" and "counsellors are strangers" acted as a barrier for them. 
Table 4. Students Barriers to Counseling $(n=90)$

\begin{tabular}{lcc}
\hline & Ranking & \% \\
\hline Confidentiality issues & 1 & 33 \\
Invasion of privacy & 2 & 31 \\
Fear of the unknown & 3 & 30 \\
Cultural difference & 4 & 23 \\
Counselors are strangers & 5 & 22 \\
Expectation to help oneself & 6 & 19 \\
Language issues & 7 & 17 \\
Stigma attached & 8 & 9 \\
Afraid of Western counseling styles & 9 & 6 \\
Religious beliefs & 9 & 6 \\
Unaware of counseling services & 9 & 6 \\
Other & - & - \\
\hline
\end{tabular}

Of the 21 students who participated in the follow-up interviews, 17 commented that "confidentiality issues" was a factor in hindering them from accessing counselling services. In this context, "confidentiality issues" related to students' fears of their personal files being disclosed to university authorities by the counsellor. This was particularly threatening for students who had not kept up with tuition fees. Others also feared that any personal information that they discussed with the counsellor would be relayed back to their parents. This disclosure heightened their level of anxiety, and consequently many students put off the idea of seeking help. Similarly, some students were concerned about being found out by their friends through the counsellor, as this could prove to be a very shameful experience for them:

Once you go and see a counsellor and your friends know, they be thinking like you have something and something that's really bad. (Sarika)

Similarly, an overwhelming majority of students interviewed, both at undergraduate and postgraduate level, described the "counsellor as a stranger," which made it extremely difficult for them to share or build a relationship between them. Students stressed that taking their problem to a "stranger" was not a culturally appropriate way for them to deal with the issue. The following statements demonstrate how some students felt about this:

I am just thinking that I will not talk about myself to someone I don't really know and they don't really know me. It is shameful to talk to someone who doesn't know our personal background. (Youqian)

Because I am not comfortable with people I don't know. It is a sharing of the concern that is the problem. You know that the counselor is a professional, but still there is that comfort issue. I just don't feel comfortable talking a stronger. (Saba)

The barrier "expectation to help oneself" was reiterated by over half of the participants (13) interviewed. These students felt the need to solve their own problems. A postgraduate student (Yumiko) put it this way: "I should have the ability to solve things myself . . . why should I go and seek advice?" Another interviewee (Saba) commented: "The expectation to help myself is very strong within me." Many students also stressed that this expectation is a cultural one:

I think generally it would be safe to say that Asian cultures are like that. The need to be strong and be able to solve your problems and not seek help from anybody else. (Saba)

Another personal barrier identified by students included "invasion of privacy." In relation to this, a number of interviewees stated that the idea of discussing their concerns with another person unknown to them felt like an "invasion of privacy":

We are not attuned to opening to strangers. When I am talking about myself to strangers about personal matters that is an invasion of my privacy. (Sharny)

There was also a general consensus among over half of the interviewees that "cultural difference" was a contributing barrier for them. Cultural difference meant a clash of understanding between them and the counsellor due to the different worldviews they held. According to interviewees, given that all counsellors are "Westerners," they are unable to relate to their issues:

The way Australians think about their problems is much different to the way we think about problems. And in turn, this affects the way they solve the problem, which I think might not be suitable with the way 
we solve the problem. (Youqian)

This barrier seems to be predominant among Indonesian, Singaporean, and Bangladeshi students. Conversely, some interviewees felt that cultural differences between the counsellor and client can be minimised if equality and respect prevailed between them. The following are comments made by female and male Bangladeshi postgraduate students respectively:

I believe I am a very open person . . . sometimes it is easier to see someone who is culturally different. (Sharny)

Cultural difference is something that can be bridged. (Rohan)

\subsection{Referral Source}

The students' responses in the questionnaire to how they accessed counselling services were classified into three groups: (1) self-referral whereby students initiated their own access $(\mathrm{n}=22 ; 22.7 \%),(2)$ referral from a professional such as a medical doctor or teaching staff such as a lecturer or tutor ( $\mathrm{n}=52 ; 57.4 \%)$, and (3) "facilitated by a friend" $(\mathrm{n}=18 ; 19.9 \%)$. Undergraduate students were more likely than graduate students to be referred by the teaching staff, and female students tended to self-refer more than male students.

Of the 21 students interviewed, 12 students sought counselling for their presenting concerns and of these, five self-referred. These students felt at ease with seeking help for their confronting issues, and one in particular felt that she had no choice left to her other than turn to someone:

I am suffering so much, I don't have friends and can't share with my family; that's why I decided to go and see a counsellor myself. (Sharny)

Another self-referring student, Yumiko, stated: "It's a concept I am comfortable with."

Other self-referred students seem to be both confident and comfortable in initiating their own referral. For another, the decision to attend counselling was voluntary:

I went by myself . . . because once my friend cannot help me, so I thought better to go and see the counselor. And I asked my parents, but they have traditional way of thinking, but my way of thinking is not like that; so I just went and sought the help of a counselor. (Yoke Pang)

Similarly, Iga commented, "No, I was not referred, I took the initiative alone."

The remaining seven students who attended counselling were referred to such services by academic staff, program coordinators, or close friends. In some instances, the referring individual (friend) had experienced a positive counselling outcome in the past and encouraged their troubled friend to attend: "One of my friends went to counselling services and she said that it helped her a lot. . . I went" (Sat). In another instance, the referrer was a friend who had had no previous contact with counselling: "My friend recommended that I should seek a counsellor, it was not a personal choice of mine to seek the counsellor" (Saba). Similarly, Mei, who had great difficulties with her academic work due to a learning disability, was referred by her lecturer: "They [lecturers] gave me advice to seek help from the counsellor regarding my disability. So I decided to go."

\subsection{Counsellor Interviews}

\subsubsection{Barriers}

Counsellors across both universities provided their perspective on what they considered hindered students from utilising counselling services. Although the promotion and marketing of counselling services at one university center has increased in recent years, one counsellor stated that "many students still find it difficult to come to counselling." The barrier, according to this counsellor, can be largely attributed to students" "lack of familiarity with the concept of counselling" and "lack of personal experience with it." Other counsellors commented:

To most students it's not part of their cultural background as a way of solving or resolving. It's not part of their frame of reference. (Jenna)

Depending where you come from, many international students don't have any idea of what counselling is. (Rose)

Other counsellors alluded to additional barriers such as "stigma and saving face" and students' inability to "share with someone they don't know." On the other hand, some stated that students' inability to "talk about their problems outside the family, or inside the family either" is another barrier. One counsellor reiterated that international students are taught to deal with the problem themselves, and students "certainly don't talk to strangers about their problems." This issue is 
well encapsulated in this comment:

Counselling is not something that they are familiar with. Many cultures that students come from, in their home culture they would never go to see a stranger for anything personal. (Theo)

However, three counsellors from the second university campus provided a different perspective and attributed the barriers to counselling to factors within counselling services and not the students. One counsellor said: "I suppose in terms of students not coming here because 'Oh, that's not what I would do,' or 'our family wouldn't do that,' I don't hear that so much anymore." Interestingly, this counsellor stated the barriers to counselling services were in their communication, advertising, and marketing strategies:

I think that despite the advertising that we do, people still don't know about us and I think that's true of local and international students. We still have students who come in and say, "I wish I knew about this in the first year." (Alina)

Similarly, another counsellor also argued that the main barrier for utilising services lay in the inefficiency of counsellors and the university in communicating the concept of counselling to students:

What is it that you do when you see a counsellor, and what is it that makes things change in your life, and how counselling helps to change it. (Jessica)

Moreover, other barriers for many students related to "issues of confidentiality," particularly for students from countries where there is a general distrust of bureaucracy. This was supported by many counsellors who, stressed that "confidentiality" is not necessarily understood by students despite the trouble and care taken to assure them that their personal matters will not be discussed with anyone without their permission. However, some counsellors noted that this barrier decreased over a period of time when the relationship and rapport develops between both parties. Interestingly, according to one counsellor, gender roles and age have the potential to become barriers to counselling, particularly for a man coming to see a female counsellor:

Some of the young men who are sure of themselves perhaps spent the first ten minutes telling me that I should be home looking after the family. Also age makes a difference; that's why I don't dye my hair anymore. As my hair is going white, even the male postgraduates will come in and they will say it's all right to talk to you. I feel as if I am talking to my mother. (Joan)

\subsubsection{Referral Source}

An important aspect of the utilisation of counselling services is how students access these. The questionnaire results demonstrated that the majority of students are referred to counselling by a number of methods. These include referral by academic staff members, medical practitioners or friends, and self-referral. This was well supported by the counsellor's interview, which reflects that referral by friends or an academic staff member seems to be the way most students enter counselling.

Some counsellors argued that this is mainly because "it is more unusual for many of the international students to come to talk to a counsellor." Furthermore, some counsellors highlighted that medical doctors refer students because often they come in with physical problems before they present with emotional problems:

Again, I know it is a mixed thing. We do have good relationships with a number of academics on this campus who will regularly refer clients over, and then others who hear by word of mouth, or they might see an advertisement in the student newsletter. Sometimes they will come in and see one of the doctors, and the doctor might refer them. So we get students by all sorts of means. (Alina)

\section{Discussion}

This study examined the ways in which international students deal with the sometimes severe emotional disturbances that they experience while studying abroad. Using a questionnaire, the study examined who students turned to in these circumstances for emotional support, their referral source, and the main barriers they identified to attend counselling services. It was found that the greatest barrier to the utilisation of counselling services were the issues of confidentiality, invasion of privacy, and the expectation to help oneself. Moreover, the majority of students were referred to counselling services by another source such as an academic staff member or medical doctor rather than self-referral. In follow up interviews, these were explored in depth and, by using counsellor-provided feedback, the study looked for concordance between the two groups. Importantly, the study found that all the 21 students who returned for in-depth interviews supported these findings from the questionnaire. 
The inadequate utilisation of counselling might be explained by students' preference for relying on friends and other international students from own country on campus for emotional support. It seems that students felt a greater connection and empathy among their friends, and despite these characteristics being a mainstay of the therapeutic approach, they were not identified in counselling context by the students. This suggests that in some students, psychological defenses related to confronting mental services for assistance were already at play and were sabotaging the therapeutic endeavors of the well-meaning counsellor. These findings relating to the utilisation of counselling services by students are largely consistent with other research studies (Aubrey, 1991; Bradley et al., 1995; Brinson \& Kottler, 1995; McKinley, Pattison, \& Gross, 1996; Yi et al., 2003). These studies have shown that overall, international students are reluctant to seek counselling services and when they do, they are generally at crisis point.

The barriers that hinder students from utilising counselling services suggest a profound difference in worldview. This may be largely be due to lack of understanding and awareness on the part of students with regard to privacy safeguards and the essential value of confidentiality exercised by counsellors in the Australian counselling setting, but which might be absent in their home country. A common anxiety voiced by many students was that the information they provided to the counsellor, would be made available to university authorities, parents, and or friends. Many feared this would be detrimental to their academic stay and personal lives. One way of alleviating this problem is for universities and in particular counselling service providers to clearly articulate their position on ethical conduct in relation to confidentiality as stipulated by their professional body - for example, the Australian Psychological Society. This clarification may dispel myths and misunderstandings by students that counsellors will disclose their private information.

Interestingly, some students assumed that they needed to disclose their entire personal history to the counsellor during counselling leading to feelings of discouragement and being overwhelmed. Many felt the counsellor would invade their personal space and consequently, many did not seek counselling despite what was an often very high level of distress. Moreover, there seems to be a lack of familiarity with the general concept of counselling as many students reiterated that counselling was not available in their home country. Given that these attitudes were not detected by many counsellors, counselling services through their various orientation programs can clearly outline the process of counselling and the benefits it offers to its clients. No doubt, this understanding is likely to reduce the drain on already stretched services.

There is evidence to suggest that many students were very uncomfortable in discussing their personal problems with someone (a counsellor) they regarded as a "stranger." While some students felt a sense of embarrassment, others believed it is not possible to effectively relate to a "stranger." These findings are inconsistent with some of the research literature. Sandhu (1994), for example, states that many international students would rather suffer with psychological difficulties than speak to a professional counsellor due to the stigma attached to counselling. Likewise, Jacobs (2001) argues that for ethnic Chinese students, issues of shame and loss of face, in particular, deter them from utilising counselling. On the contrary, the findings of this study demonstrate that only 17 percent of students stated that "stigma" was a barrier for them in utilising counselling services.

Mori (2002) found three barriers that hinder students from utilising counselling services; these include cultural differences in basic beliefs about mental health problems, unfamiliarity with basic concept of counselling, and unawareness of the existence of services. To a certain extent, the findings of this study confirm Mori's argument that "cultural differences" may be a hindrance for students in accessing counselling services. Under a quarter of the students (23\%) stated that "cultural differences" affects their utilisation of counselling services. However, although some students remarked on their unfamiliarity with the concept of counselling, this was not a barrier to counselling. The present study also disagrees with Mori's findings that unawareness of the existence of services is a barrier to counselling. On the contrary, of the 90 participants who completed the questionnaire, only six percent reported their unawareness of the campus counselling services. It is very clear that both universities are promoting their services effectively through different mediums but more through the student diary.

Although there are few similarities between the counsellor's and student's perspectives relating to the barriers to the utilisation of counselling services by students, there are many differences between them. Barriers such as "stigma," "saving face," and "religion" were not stated by the students. This demonstrates a mismatch between the two groups and clearly highlights the need for counsellors to become more aware of the nature of barriers that hinder students from accessing the services. This study showed that more than half of the students were referred by another individual to counselling services. It is evident that drawing on professional help is not the first port of call for students. Generally, students will try to resolve their problems by seeking out a friend and or other international students. According to the counsellors interviewed, some students somatise their discomfort in physical form and hence attend medical services 
for their complaint. This opens the opportunity for medical doctors to refer them to counselling services. Sometimes, friends who had previous good experience with counselling refer their troubled friend to attend. It also seems that there is a common understanding between counsellors and students regarding the referral source for counselling services.

In conclusion, it is evidently clear from the findings that the under-utilisation of counselling services is largely to do with the students being international students who bring with them their cultural values to another context with which is very unfamiliar.

\section{Conclusion}

The present research had several limitations. Firstly, the low sample size of male students in the interviews did not allow greater insights into how male students experienced the utilisation of counselling in comparison to females, or what they reported at counselling. The recruitment of male participants in this context was very difficult and could have been due to cultural values or whether, in general, men may find it difficult to share personal counselling experiences. The low response rate limits the generalizability of the findings. Secondly, this study was confined to two large urban campuses. It would be useful to conduct further studies to ascertain whether students at similar and/or regional universities have similar issues. Thirdly, the language difficulties of the students at times hindered them from clarifying and elaborating on particular items of concern such as the barriers to counselling. The small data set of the study does not permit extrapolation for the entire international student population, but does shed light on the experiences of the students interviewed and suggests some changes for counsellors and counselling services.

To conclude, this study contributes to the current knowledge of international students' utilisation of counselling services in an Australian context by providing insights into their help-seeking behavior, referral resource, and the barriers that hinder them from seeking counselling. Given that it may seem that counsellors are unaware of the assumptions students have about counselling services, these findings alert them to this crucial aspect of their work and enables them to reduce its impact by heightening their own self-awareness. This can be achieved both in counselling encounters and at various orientation programs such as those delivered by counselling services. Finally, the study alludes to the urgent need to develop more culturally responsive counselling services that could lead to their increased utilisation.

\section{References}

Arthur, N. (2004). Counselling international students: Clients from around the world. New York: Kluwer Academic/Plenum Publishers. http://dx.doi.org/10.1007/978-1-4419-8919-2

Aubrey, R. (1991). International students on campus: A challenge for counselors, medical providers, and clinicians. Smith College Studies in Social Work, 62(1), 20-33. http://dx.doi.org/10.1080/00377319109516697

Australian Education International (AEI). (2009). International students enrolments in higher education. Retrieved from http://www.aei.gov.au/research/International-Student-Data/Pages/default.aspx

Bayley, S., Fearnside, R., Arnol, J., Misiano, J., \& Rottura, R. (2002). International students in Victorian universities. People and Place, 10(2), 45.

Bradley, L., Parr, G., Lan, W. Y., Bingi, R., \& Gould, L. J. (1995). Counselling expectations of international students. International Journal for the Advancement of Counselling, 18, 21-31. http://dx.doi.org/10.1007/BF01409601

Brinson, J. A., \& Kottler, J. (1995). International students in counselling: Some alternative models. Journal of College Student Psychotherapy, 9(3), 57-70. http://dx.doi.org/10.1300/J035v09n03_05

Hechanova-Alampay, R., Beehr, T. A., Christiansen, N. D., \& Horn, R. K. V. (2002). Adjustment and strain among domestic and international student sojourners: A longitudinal study. School Psychology International, 23(4), 458-474. http://dx.doi.org/10.1177/0143034302234007

Kambouropoulos, A. (2008). The cross cultural counselling experience: An investigation of perspectives of international students and counsellors. (Unpublished doctoral dissertation). Monash University, Melbourne.

Lin, J. C. G. (1996). Counseling college students from Taiwan. In P. Pedersen \& D. Locke (Eds.), Cultural and diversity issues in counseling (pp. 51-53). Greensboro, NC: ERIC/CASS Publications.

Lin, J. G., \& Yi, J. M. (1997). Asian international students' adjustment: Issues and program suggestions. College Student Journal, 31, 473-479.

McKinley, N. J., Pattison, H. M., \& Gross, H. (1996). An exploratory investigation of the effects of a cultural 
orientation programme on the psychological well-being of international university students. Higher Education, 31, 137-144. http://dx.doi.org/10.1007/bf00128438

Merriam, S. (2002). Qualitative research in practice: Examples for discussion and analysis. San Francisco: Jossey-Bass.

Mori, S. (2002). Addressing the mental health concerns of international students. Journal of Counseling and Development, 78, 137-144. http://dx.doi.org/10.1002/j.1556-6676.2000.tb02571.x

Nilsson, J. E., Berkel, A. L., \& Lucas, S. M. (2004).Utilization rate and presenting concerns of international students at a university counselling centre: Implications for outreach programming. Journal of College Students Psychotherapy, 19(2), 49-59. http://dx.doi.org/10.1300/J035v19n02_05

Poyrazli, S., Arbona, C., Bullington, R., \& Pisecco, S. (2001). Adjustment issues of Turkish college students studying in the United States. College Student Journal, 35(1), 52-62.

Robinson, T. L., \& Howard-Hamilton, M. F. (2000). The convergence of race, ethnicity, and gender. Columbus, OH: Merrill.

Sandhu, D. S. (1994). An examination of the psychological needs of the international students: Implications for counselling and psychotherapy. International Journal for the Advancement of Counseling, 17, 229-239. http://dx.doi.org/10.1007/BF01407739

Sue, S., Zane, N., \& Young, K. (1994). Research on psychotherapy with culturally diverse populations. In A. E. Bergin \& S. L. Garfield (Eds.), Handbook of psychotherapy and behavior change (4th ed.), (pp. 789-817). New York: John Wiley.

Uba, L. (1994). Asian Americans: Personality patterns, identity, and mental health. New York: Guilford Press.

Yi, J. K., Lin, J. G., \& Kishimoto, Y. (2003). Utilization of counseling services by international students. Journal of Instructional Psychology, 30(4), 333-342. 